\title{
Risks and Challenges of the Transition to an Integrated Geothermal Concept for the Göttingen University Campus
}

\author{
Bernd Leiss $^{1,2}$, Dmitry Romanov ${ }^{2,3}$, Bianca Wagner ${ }^{1,2}$ \\ ${ }^{1}$ Geoscience Centre of the University of Göttingen, Goldschmidtstraße 3, 37077 Göttingen, Germany \\ ${ }^{2}$ Universitätsenergie Göttingen GmbH, Hospitalstraße 3, 37073 Göttingen, Germany \\ ${ }^{3}$ HAWK (University of Applied Sciences And Arts Hildesheim/Holzminden/Göttingen), Rudolf- \\ Diesel-Straße 12, Göttingen, 37075, Germany
}

Keywords: Integrated Geothermal Systems, EGS, energy transition concept.

\begin{abstract}
:
This study presents the main strategic risks and challenges to be faced during the prospective transition from the existing fossil fuel-based energy system to an integrated „Enhanced Geothermal Systems" -concept, which includes deep, medium, and shallow geothermal energy, for district heating and cooling of the Göttingen university campus (demo site of the EU-HORIZON2020-project MEET). Such an innovative integrated concept aims for lowering the financial risks and maximizing decarbonisation effects. The geological and technical preconditions of the demo site are analyzed, and a basic conceptual scheme is suggested. To overcome the challenges of the implementation of such a complex system, an intensive cooperation between all stakeholders, coherent planning and financing, and a modular, step-by-step approach is a prerequisite.
\end{abstract}




\section{Introduction}

"Enhanced Geothermal Systems (EGS)" allow for the exploration, exploitation and utilization of deep geothermal energy in a much wider geographical area range rather than just in the naturally predestined areas with high geothermal gradients and high permeabilities of the target horizons. In that context, the EU-Horizon 2020 project MEET (Multidisciplinary and multi-context demonstration of EGS exploration and Exploitation Techniques and potentials) aims to analyze the potential of EGS in different representative geological settings of Variscan grantitic, metasedimentary and -volcanic rocks within Europe and to integrate such EGS in energy systems (e.g., Trullenque et al., 2018; Dalmais et al., 2019). The University campus of Göttingen in Germany is one of the four demo sites of the project, which is supposed to develop an EGS concept in deformed metasedimentary rocks to integrate deep geothermal energy into the existing district heating (DH) system.

Besides the geoscientific and -technical challenges, there are two additional major issues, strongly hampering the implementation of such an approach:

- Due to the relatively low energy density and the geological and technical risks, the financing of the drilling costs is, in general, the biggest hurdle. In the case of such an innovative and pioneering EGS approach as in our case, an even more sophisticated concept is needed to minimize economic risks for convincing investors.

- Due to the complex preparatory studies and the high investment barriers, it is difficult to set up a reliable, long-term timeline planning as well as to give estimations on the success rate. From this follows the need of an energy transition concept to harmonize the life cycle of the existing energy supply sources with the development of the geothermal systems to avoid additional costs by maintaining e.g. excessive backup systems for a long time and to be prepared for the case of no success.

This study investigates the surface and subsurface potentials at the real demo site - the Göttingen campus - for a holistic and sustainable approach for a significant decarbonisation of heat and cold supply systems by coupling them to geothermal systems.

\section{Geological setting}

There is only limited data on the deeper geological underground below Göttingen since there are only a very few exploration wells in the wider area of the city with a depth of max. 1,500 m. In 2015, a seismic campaign with two profiles crossing the campus area and an exploration depth of 1,500 $\mathrm{m}$ could validate that the upper several thousand meters of the subsurface of Göttingen are built up of three main units (Leiss et. al 2011). For the lowermost unit (1) below 1,500 m, it can be concluded from the general geological setting of the wider area, that it represents low-grade metamorphic basement mainly consisting of Devonian and Carboniferous metasedimentary and -volcanic successions (greywackes, slates, quartzites, cherts, diabase) that have been folded and thrusted during the Variscan Orogeny in the late Carboniferous. On top of the basement unit follows a Permian sedimentary sequence (2) starting with either no or only locally deposited metavolcanics or sandstones of the Rotliegend as well as sequences of rock salt, potash salt, anhydrite, dolomite and clay-dominated layers of the Zechstein age reaching a thickness up to several hundred meters. The uppermost major unit (3) comprises the sedimentary cover of 500 to $800 \mathrm{~m}$ thickness made up mainly of sandstones, clay rocks and limestones of Triassic age (Buntsandstein, Muschelkalk and Keuper). The whole sequence is overprinted tectonically by the north-south striking Leinetal Graben structure that developed during Mesozoic to Cenozoic times. Whether the faults continue into the Variscan basement or are decoupled mechanically by the Zechstein successions and possibly located elsewhere, is still not clear. Within the Leinetal Graben structure, Quarternary alluvial and wind-carried sediments are forming an additional unit of minor thickness, but of importance regarding the utilization of geothermal systems.

The quite complex and relatively poorly investigated geological setting as well as the unconventional geothermal reservoirs demonstrate the very early stage of exploration at the Göttingen Campus site. At the same time, the different lithological and structural units offer the chance of exploiting different horizons for the utilization of different geothermal systems, possibly allowing an increased efficiency: 
- a deep geothermal system in the Variscan basement at a depth between 3,000 to 5,000 $\mathrm{m}$ for the needs of supplying heat to the DH system of the campus (the reservoir characterization and modelling is under way within the MEET-project).

- a medium deep geothermal system in the Zechstein successions or the overlying sandstone layers at a depth between around 500 and $1,300 \mathrm{~m}$ to realize a seasonal heat storage system.

- $\quad$ shallow geothermal systems mainly for cooling purposes in the partly water-saturated quartenary alluvial sediments and karstified Mesozoic carbonates (existing systems, test-field and potential maps).

\section{Technical background}

The campus of the Georg-August-University (UGOE) and University Medical Centre (UMG) takes large area in the center and in the north of the city of Göttingen. The campus' main energy supplier is the combined heat and power (CHP) plant, which includes a gas turbine and several steam and hot water boilers. The Sankey Diagram for the balanced energy flow of 2018 is shown in Figure 1. Natural gas consumption is slightly higher than $350 \mathrm{GWh} / \mathrm{a}$. Apart from electricity and heat for district heating, the UMG also needs steam and cold. The latter is produced by both vapor compression and absorption cooling machines. Current design district heating load and design cooling load are estimated at 44.5 MW and 16.5 MW, respectively. The complete renewal of the UMG-buildings within at least the next 15 years and the soon-expected end of the turbine lifetime put a question to UGOE and UMG on how the future concept of their energy supply with a maximum share of renewables should look like.

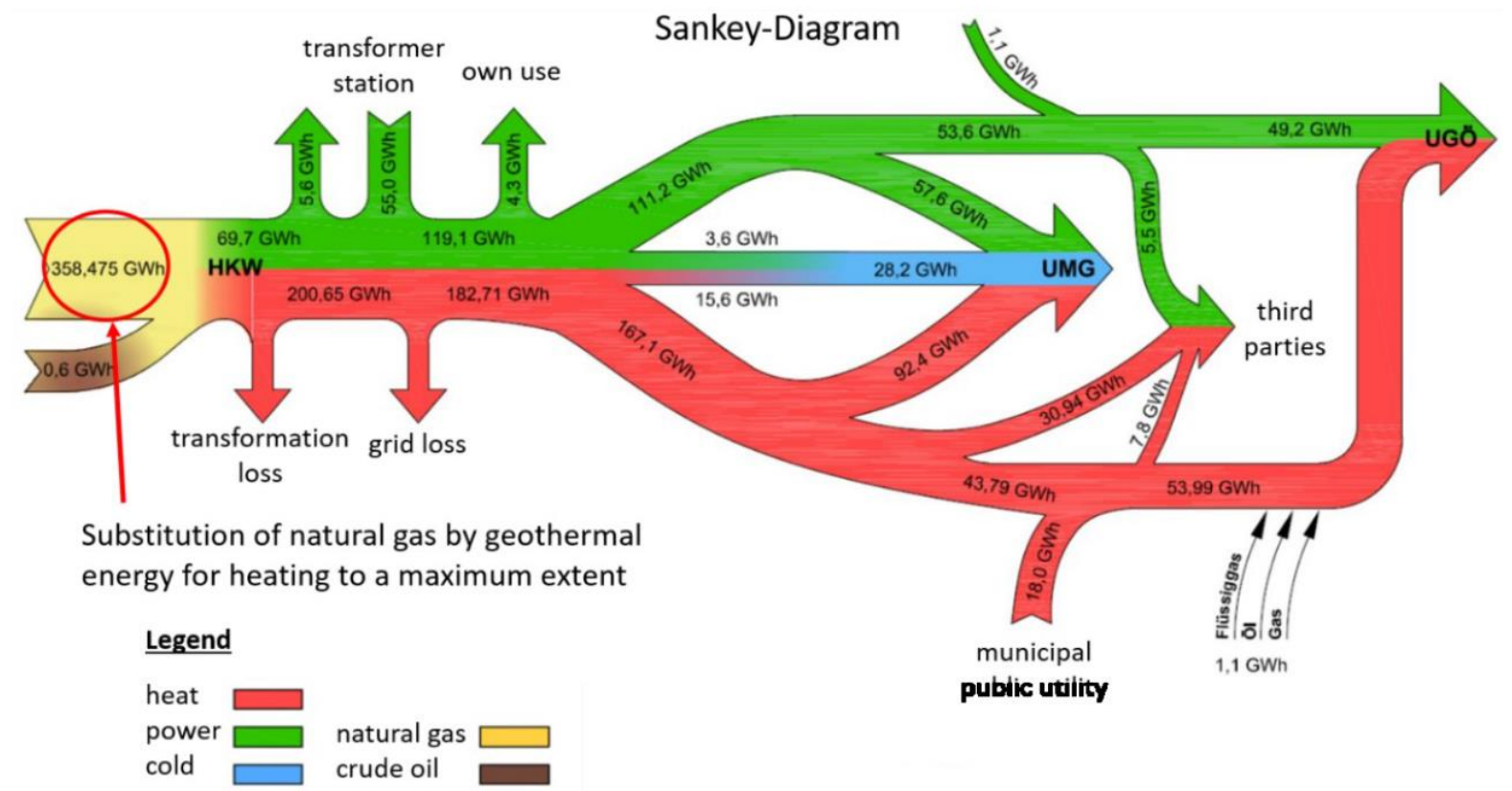

Figure 1 Energy balance of the Göttingen University campus in 2018 (after Energiebericht 2018).

\section{Discussion: Integrated geothermal concept for district heating and cooling of the campus}

The development of an EGS is in general a challenging task in view of the geological, technical and financial risks. To develop and exploit a deep geothermal system in the folded and thrusted metasediments, as expected below the Göttingen campus, is especially challenging since it requires an innovative reservoir characterisation approach including the development of a previously not tested stimulation concept for improving the permeability. The highest barrier of the realization of such a project is to get a research well financed by investors and research funds in order to predict the final success (or failure) of the project on the earliest stages of exploration. To better justify such a research well with a depth of at least 2,000 m, we include the exploration of the medium depth geothermal units of the Zechstein salt horizon and the overlying sandstones for the development of thermal energy storage systems (aquifer, cavern or borehole-based). Not only the geological setting is well suited for such a concept, but also the future surface infrastructure development in regard to the to-be-built 
Medical Center provides very suitable conditions. A closed water-based air-conditioning, as it is recommended for medical buildings to better avoid germ spreading, represents an additional opportunity to implement shallow geothermal system.

Another barrier for the development of such a complex deep geothermal system is the uncertainty in the prediction of the starting time and the rate of questionable successful production. This collides with the time line planning of the substitution of the existing gas turbine. The recent implementation of several decentralized CHPs of small output is seen as a perfect basis to create a long-term, flexible modular system to later integrate the deep geothermal heat energy in a customized way by keeping backups to guarantee the security of supply.

The basic conceptual scheme (Figure 2) summarizes the above proposed integrated utilization of the various types of geothermal energy for the Göttingen demo site. It includes the three different subsurface depth levels: deep ( $>3,500 \mathrm{~m})$, medium $(200$ to 1,500 m) and shallow ( $<150 \mathrm{~m})$. The design cooling load for the to-be-built buildings is estimated at $2.8 \mathrm{MW}$, which can partially be met by the shallow geothermal energy via direct cooling. Also the heat pumps for the shallow geothermal energy can be used in winter so that the brine is pumped to the evaporator and low or ultra-low temperature heat produced in the condenser for corresponding buildings. The medium geothermal level can be utilized for a seasonal thermal energy storage (TES) in cases when the waste heat of the campus should be stored (data center, condensers of cooling machines). Later the stored energy can be recovered for preheating the heat carrier for low-temperature consumers. Deep geothermal energy can cover a part of the heating demand of the campus. Currently, the campus' heat supply system is designed for high temperature heat carrier (up to $120^{\circ} \mathrm{C}$ ) which is a hindrance to the integration of renewable energy sources in general and, particularly, geothermal energy. However, the long-term planning of the campus development should consider a heat supply system adjusted to low temperature heat carrier (up to 75 $\left.{ }^{\circ} \mathrm{C}\right)$. That is why the scheme contains two separate heat exchangers and circuits for high temperature (HTDH) and low temperature district heating (LTDH), respectively. In case of low temperature of the brine, low heat output from geothermal well or during maintenance, both circuits can be backed up by decentralized fossil fuel-based CHPs or peak boilers. Moreover, a heat pump is considered in the low temperature circuit as a temperature booster in case the temperature of the brine after the LTDH heat exchanger is too low. Additionally, deep geothermal energy is supposed to be used for absorption cooling, which is currently supplied by fossil fuels burning, thus compensating for the drop of space heating demand in summer.

Given that geological conditions are, to some extent, not well known and previously not used for geothermal energy exploration, the wellhead temperature and the mass flow rate of the brine are assumed to be from 80 to $130{ }^{\circ} \mathrm{C}$ and from 0 to $45 \mathrm{l} / \mathrm{s}$, respectively. The reinjection temperature is assumed to be $50{ }^{\circ} \mathrm{C}$. All aforementioned parameters lead to the heat output varying from 0 to $15 \mathrm{MW}$. At the same time the design heat load of the to-be-built buildings is estimated at $32.6 \mathrm{MW}$, i.e. in the best case scenario, deep geothermal energy can cover about a half of this load. Moreover, since the heat output of a geothermal plant has almost no fluctuations, and the heat load of DH system, on the contrary, changes significantly throughout a year, it will be possible to replace some of the heat and cold energy generated by the existing fossil fuel-based systems of the campus.

\section{Conclusion and outlook}

For the heat and cold supply of the Göttingen campus, there is a potential for the utilization of an integrated geothermal concept to minimize the exploitation risks, maximize decarbonisation and make the project attractive for investors. Additionally, the surface infrastructure of the existing DH system can be exploited. However, such integrated systems quickly reach complexity levels, which needs intensive cooperation between all players as well as elaboration of converging processes related to the time lines of the different planning and financing teams. This mainly results from the subsurfaceinduced uncertainties, which in our view, can be only compensated by a smart modular system. Such a modular system is supposed to allow a continuous, step-by-step adaptation to the geothermal 
exploration and exploitation results, which is the key issue for the advanced integration of geothermal energy in existing energy supply systems. In this sense, the demo site Göttingen can be a front runner.

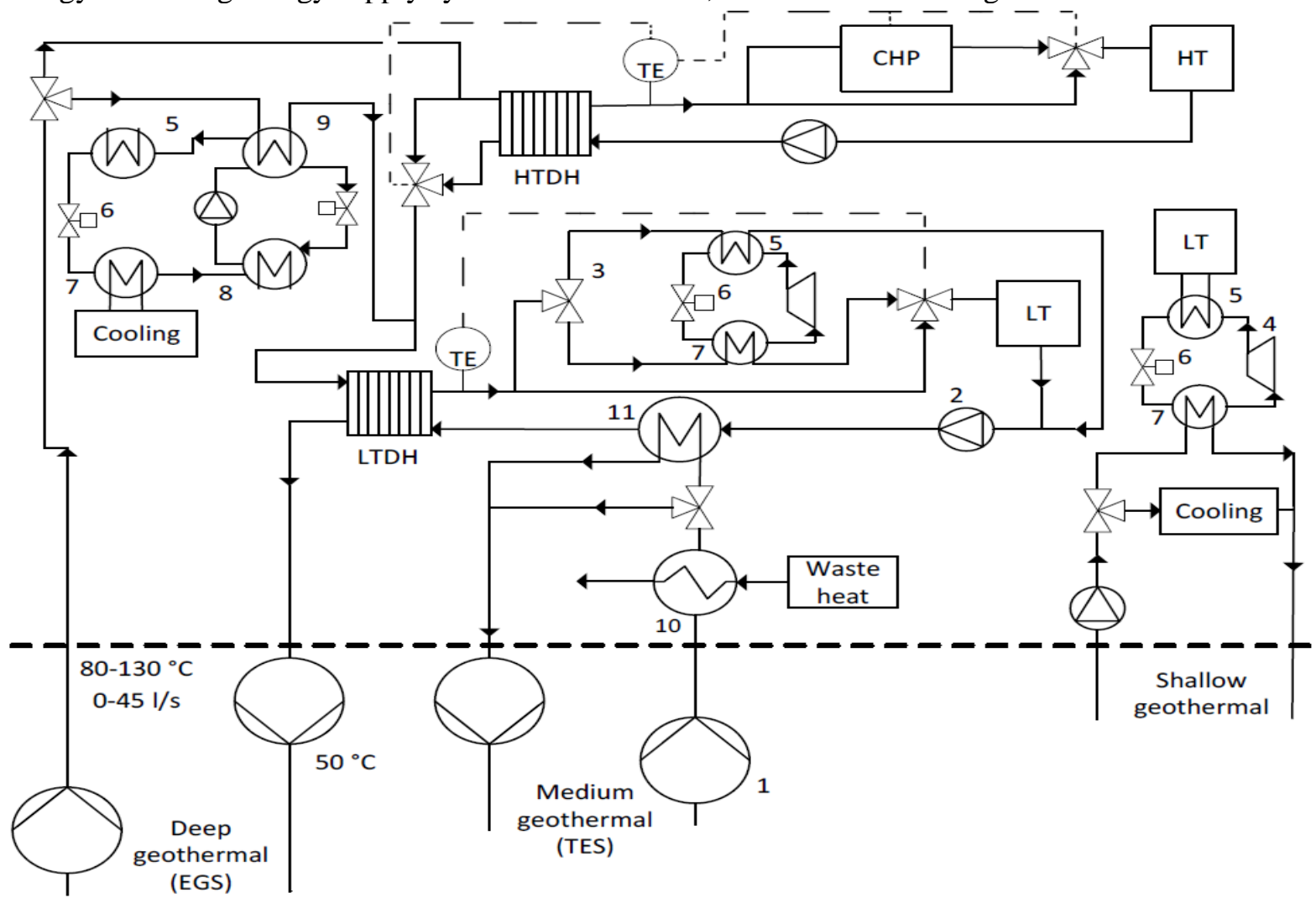

Figure 2 The basic conceptual scheme of integrated utilization of geothermal energy for the Göttingen demo site. 1 - submersible pump; 2 - circulating pump; 3 - control valve; 4 - compressor; 5 condenser; 6 - throttle valve; 7 - evaporator; 8 -absorber; 9 - generator; 10 - recuperator; 11 preheater; TE - temperature sensor; $H T(D H)$ and $L T(D H)$ - high-and low-temperature consumers (heat exchangers).

\section{Acknowledgements}

This work has received funding from the European Union's Horizon 2020 research and innovation programme (grant agreement № 792037 - MEET Project).

\section{References}

Dalmais, E., Genter, A., Trullenque, G., Leoutre, E., Leiss, B., Wagner, B., Mintsa, A. C., Bär, K., and Rajsl, I. [2019]. MEET Project: Toward the spreading of EGS across Europe. European Geothermal Congress 2019, 8.

Energiebericht 2018 [2019]. Georg-August-Universität Stiftung Öffentlichen Rechts (ed.). Annual report. https://www.umg.eu/fileadmin/Redaktion/Dachportal/006_Ueber_uns/id143_Vorstand/id798_ Geschaeftsbereiche/id801_G3-3_Gebaeudemanagement/Energiebericht_2018.pdf. (Accessed: 25 June 2020).

Leiss, B., Vollbrecht, A., Tanner, D., Wemmer, K. [2011]. Tiefengeothermisches Potential in der Region Göttingen - geologische Rahmenbedingungen.- In: Leiss, B., Vollbrecht, A., Tanner, D., Arp, G.: Neue Untersuchungen zur Geologie der Leinetalgrabenstruktur - Bausteine zur Erkundung des geothermischen Nutzungspotentials in der Region Göttingen,163-170, Universitätsdrucke Göttingen.

Trullenque, G., Genter, A., Leiss, B., Wagner, B., Bouchet, R., Léoutre, E., Malnar, B., Bär, K. and Rajšl, I. [2018]. Upscaling of EGS in Different Geological Conditions: a European Perspective. Proc. 43rd Workshop Geothermal Reservoir Engineering Stanford Univ., Stanford, California, SGP-TR-213. 